\title{
Hand Grip Strength in Students: Differences in the Gender Dimorphism
}

\author{
Ratko Pavlovića, *, Mensur Vrcić ${ }^{\text {b }}$ \\ ${ }^{a}$ Faculty of Physical Education and Sport, University East Sarajevo, 71420 Pale, East Sarajevo, Bosnia and Herzegovina \\ ${ }^{b}$ Faculty of Physical Education and Sport, University Sarajevo, 71000 Sarajevo, Bosnia and Herzegovina \\ *Corresponding author Email: pavlovicratko@yahoo.com \\ DOI: https://doi.org/10.34256/ijpefs2143
}

Received: 15-09-2021, Revised: 08-10-2021; Accepted: 10-10-2021; Published: 18-10-2021

\begin{abstract}
The hands are anatomically specialized for manipulative tasks with different physical objects, where they can cope with certain loads with different forces and intensity. During various physical and sports activities, the hands produce the appropriate muscular force for gripping, which manifests as the hand grip's force. For this reason, hand grip strength (HGS) is recognized as a limiting factor in all manipulative activities performed by the cranial part of the body. The current research included a sample of 22 subjects, 16 male Body Height $(B H=180.28 \pm 4.65 \mathrm{~cm}) ;$ Body Weight $(B W=80.05 \pm 9.96 \mathrm{~kg})$, Body Mass Index $\left(B M I=24.61 \pm 2.74 \mathrm{~kg} / \mathrm{m}^{2}\right)$ and 6 female subjects Body Height $(B H=167.42 \pm 11.11 \mathrm{~cm})$; Body Weight $(B W=64.80 \pm 10.09 \mathrm{~kg})$; Body Mass Index $\left(B M I=23.02 \pm 1.57 \mathrm{~kg} / \mathrm{m}^{2}\right)$ on the third year of study at the Faculty of Physical Education and Sports. This study aimed to determine the maximum isometric muscle force of the handgrip and differences between the same gender of students. A t-test for small samples was applied for data processing, and the relevant statistical parameters were calculated. The obtained t-test results confirmed statistically significant differences between the so-called dominant and non-dominant hands in male subjects $(t=4.158 ; p<0.05)$ and female subjects $(t=3.176$; $\mathrm{p}$ <0.05). The obtained results of this research will be used for analytical and diagnostic purposes with a wide range of activities in the population of physical education and sports students (assessment of physical ability, trends, and tendencies to monitor and change abilities, influence on the implementation of certain curricula of some subjects studied at the faculty, etc.).
\end{abstract}

Keywords: Hand grip strength, Students, Dimorphism, Physical Education, Sports Students

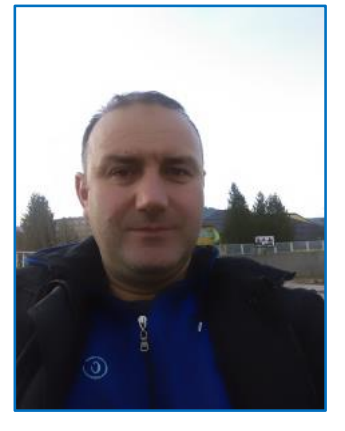

Prof. Ratko Pavlović is a full professor of Sports and Rehabilitation Sciences at the University of East Sarajevo. He published about 230 scientific papers, is the author of 5 textbooks on Athletics. Also, he serves as a member of the editorial board of 88 international scientific journals (Chief-in-editor of 7 international journals). Reviewer of several textbooks and international journals. He is a member of more international scientific organizations, which includes Athens Institute for Education and Research \& World Association of Academics and Researcher; International Organization for Health, Sports and Kinesiology; The International Society of Biomechanics in Sports; World Academy of Science, Engineering and Technology,
Science Research Association and the Global Academic Organization; Sports Medicine Association of Serbia. Participant in an international project,"Attitudes toward gender equality in football in the school context" (University of Castilla La Mancha, Espana). His current research interests are Sports and rehabilitation science, Track and Field, Motor Control, Motor skills, Physical education, Biomechanics in Sport.

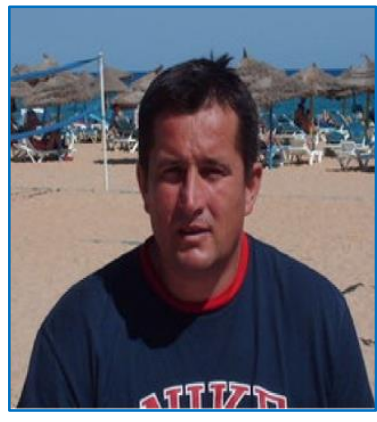

Prof. Mensur Vrcić is currently an associate professor at the Department of Sports and Methodology, Faculty of Sports and Physical Education in Sarajevo. Author of the book Fitness-individual programs, co-author of two books, and 
author of numerous scientific and professional papers in reference journals, congresses, symposia. He has published a large number of papers in athletic disciplines. He was actively involved in athletics in the period 1981-1991 and 1996-2000. He also worked as a coach in athletics (participant in world, European and other championships). His current research interests are Sports Science, Sports recreation, Methodology, Fitness, Motor skills.

\section{Introduction}

The hand is the basic manipulative organ of the human body and the force of squeezing the hands, as a limiting factor, participates in all manipulative activities performed by the cranial part of the body [1]. The HGS test is considered the gold standard for measuring the mechanical characteristics of muscles, and is an objective method of assessing the integrity of cranial segments and represents a physiological variable that is influenced by numerous factors (age, gender, and body size). According to Carreira et al., [2] it is one of the most important universal and best indicators of functional, nutritional and health status [2-4]. HGS is a general term used by athletes, and refers to the muscular strength and force they can create with their hands whose strength is estimated by dynamometry. It results in strong bending of all finger, thumb, and wrist joints with the maximum force a subject can exert under normal biokinetic conditions [5]. Also, according to Beloosesky et al., [6] it is a very important component in hand rehabilitation because it often assesses the initial limitation of the patient in comparison with the valid norms. It can be used in the investigation and monitoring of patients with neuromuscular disease. The authors Gunther et al., [7] consider that loss of strength is most often associated with a decrease in muscle cross-section and various degenerative changes in the joints. According to Dopsaj, et al., [8], the force of hand grip is one of the most important data on contractile capacity and isometric characteristics of the value of the force that develops as a function of time. The achieved force of $100 \%$ is an indicator of the developmental capacity of the contractile potential at the level of maximum muscle contraction and is an indicator of the developmental ability of the basic explosive force of hand grip. According to Bohannon [9], hand strength is correlated with other muscle groups, including caudal limb muscles, so it is a valid indicator of a person's overall physical strength. A strong correlation between grip strength and different anthropometric properties has been investigated by numerous authors [10-13]. Recently published reviews of the study suggest that lower levels of physical ability are associated with a higher risk of subsequent health problems. Weaker grip strength and slower walking speeds have been found to be associated with an increased risk of future bone fractures and cognitive decline during aging [14]. There is also strong scientific evidence on evolutionary and genetic relationships and patterns between the quality of hand grip strength as a suitable phenotype for identifying genetic variants relevant to the physical functioning of middle and old age [15].

Assessing hand grip strength is gaining importance in a number of situations, while in many sports this grip strength has been established as a secondary function. However, numerous studies show that arm strength is a very important component, especially in some sports: sport climbing, judo, handball, weightlifting, wrestling, tennis, field hockey, bowling, cricket, taekwondo, baseball, Nordic running, etc. [16-20]. In accordance to Koley et al., [21] the dominant hand is considered to be the one that is used more often, which is faster and more precise when performing various manual tasks. The characteristics of the hand grip are relatively predictable because they are directly related to the morphological structure, degree of training, fitness, health and physiological condition at the time of testing. Dominant lateralization means the appearance of the leading limb or the leading sense when performing complex psychomotor activities, where when performing the activity, the right hand conducts bimanual activity, and the left hand follows it. Incel et al., [22] confirm that the grip strength is higher in the dominant hand in righthanded people, while for left-handed people such significant differences between the parties have not been confirmed. Also, research by Dopsaj et al., [23] confirms that men have a significantly higher maximum grip force in both dominant and non-dominant arms than women, due to higher muscle mass which represents higher muscle contractile potential while women show greater muscular endurance [24]. It has been proven that women perform physical work, especially by type of endurance, with greater energy efficiency, because the given mechanism is based on the phenomenon that they have a higher coefficient of respiratory exchange during submaximal exercise. Estrogen affects "fuel" metabolism during exercise in terms of glycogen savings and increases blood flow in active muscle, while the neuromuscular system of women shows a tendency to adapt more easily to changes in the level of the locomotor system [25]. The 
grip strength of the right and left arms is positively correlated with weight, height, and body surface area. It has been confirmed that the grip strength of the hands significantly defines the mineral content in the bones and bone surfaces at the forearm sites and that they have a positive correlation with active body weight and physical activity [26]. From a practical point of view, the corresponding contractile characteristics of the grip strength, especially the level of maximum force, represent an indicator of the developmental ability of the basic active functional limb (arm) which represents the anatomically specialized organ of the kinetic chain end. Various authors have investigated the maximum isometric force and its dimensions [23, 27-30] in order to define the basic characteristics of the model with respect to functional and gender dimorphism at maximum isometric handshake in welltrained athletes for analytical and diagnostic purposes $[17,23,31-34]$. From the point of view of cybernetics in sports, and in order to develop methods for control and assessment of physical ability, it is necessary to define models for assessing the actual state of development of a given limb and its corresponding muscle group. These models greatly help in the classification and diagnostic definition of the development of the level or deficit of contractile ability in order to provide relevant information that influences the trainer and strategic training decisions [30]. Given the fact that students of physical education and sports are physically healthy and active population that through the study program realizes certain physical and sports activities in which there is an expression of grip strength, it was interesting to examine the maximum isometric force (handshake) in both genders and possible mutual differences in strength. The main goal of the study was to determine the maximum isometric muscle strength of the hand grip and the differences in terms of gender dimorphism of the thirdyear students of the Faculty of Physical Education and Sports.

\section{Materials and Methods}

\subsection{Participants}

The research included a sample of 22 subjects, 16 male $(B H=180,28 \pm 4,65 \mathrm{~cm} ; \quad B W=80,05 \pm 9,96 \mathrm{~kg}$, $\left.\mathrm{BMI}=24,61 \pm 2,74 \mathrm{~kg} / \mathrm{m}^{2}\right)$ and 6 female subjects $(\mathrm{BH}=167,42 \pm 11,11 \mathrm{~cm} ; \quad \mathrm{BW}=64,80 \pm 10,09 \mathrm{~kg}$; $B M I=23,02 \pm 1,57 \mathrm{~kg} / \mathrm{m}^{2}$ ) on the third year of study at the Faculty of Physical Education and Sports in East Sarajevo. At the time of measurement, all were physically healthy and were familiar with the test conditions. The inclusion criteria were that there was no restriction of movement in the upper extremities, inflammatory joint diseases or neurological disorders. The dominant hand is defined as the one that is preferred for everyday activities (writing, eating, handling heavy objects). No participants reported ambidexterity. The study was conducted with the voluntary consent of all participants. The research was conducted in accordance with the professional and ethical standards of the Declaration of Helsinki.

\subsection{Study Design}

The muscular force of the flexors of the fingers of the hand was measured by the method of isometric dynamometry in laboratory conditions where a standardized test - hand grip was used. The testing procedure was conducted in accordance with the defined recommendations of the American Society of Hands Therapists [35]. The force realized at maximum hand grip (dynamometry) was measured using a digital hand dynamometer CAMRY-EH101, USA (Picture 1). Dynamometry of the hand was performed by holding the subject dynamometer in one hand (bent at the elbow joint at $90^{\circ}$ ) while the other hand was resting on the thigh. The subject was then instructed to squeeze the dynamometer as tightly as possible, using the musculature of the hand. He tried to achieve the best possible result with the maximum strong grip. Each subject performed two attempts with a stronger and weaker hand, and as relevant for statistical processing, a better result was recorded. The results are expressed in kilograms $(\mathrm{kg})$ with a measurement accuracy of 0.01 kg. Calibration of the instrument was performed periodically during the study.

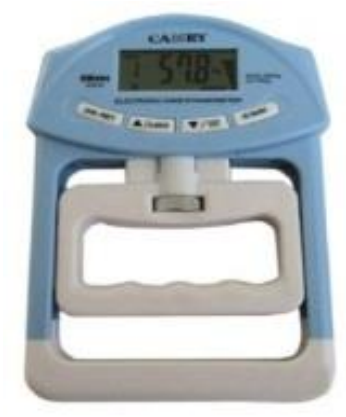

Picture 1 CAMRY- Digital Hand Dynamometer, 200lb, EH101, USA.

\subsection{Statistical analysis}

Basic central and dispersion parameters were calculated for each variable. The Kolmogorov-Smirnov test was applied to confirm normality. The data were analyzed using student's $\mathrm{T}$ - test and statistical significance was set at level $p<0,01 ; p<0.05$. Statistical 
procedures and analyses were conducted using the statistical package STATISTICA 10.0 for Windows (Stat Soft, Inc., Tulsa).

\section{Result}

Table 1 contains the basic statistical parameters of maximum hand grip strength for male and female samples, and the normality of the distribution of results was determined by K-S test, which is a prerequisite for the application of parametric statistical procedures.
The average maximum grip strength with the right hand of male students was $49.10 \pm 6.63 \mathrm{~kg}$, and with the left it was $46.08 \pm 6.37 \mathrm{~kg}$. The minimum strength achieved with the right hand is $38.30 \mathrm{~kg}$, and the maximum is $61.90 \mathrm{~kg}$ in the range of $23.60 \mathrm{~kg}$. The maximum achieved strength of men with the left hand is $54.10 \mathrm{~kg}$, and the minimum is $35.20 \mathrm{~kg}$ in the range of $18.90 \mathrm{~kg}$. CV\% values of male students ranged from 13.50 to 13.82 . The girls achieved an average grip strength of $35.6 \pm 4.91 \mathrm{~kg}$ with their right hand and $31.6 \pm 3.87 \mathrm{~kg}$ with their left.

Table 1 Descriptive Statistics

\begin{tabular}{|c|c|c|c|c|c|c|c|c|c|c|}
\hline Variable & Gender & Mean & Min & Max & Range & SD & CV\% & Skew & Kurt & K-S \\
\hline $\begin{array}{c}\text { Right } \\
\text { hand (kg) }\end{array}$ & Male & 49,10 & 38,30 & 61,90 & 23,60 & 6,63 & 13,50 & 0,34 & $-0,41$ & 0,125 \\
\cline { 2 - 11 } & Female & 35,6 & 28,9 & 42,2 & 13,30 & 4,91 & 13,80 & $-0,16$ & $-0,97$ & 0,128 \\
\hline \multirow{2}{*}{$\begin{array}{c}\text { Left } \\
\text { hand (kg) }\end{array}$} & Male & 46,08 & 35,20 & 54,10 & 18,90 & 6,37 & 13,82 & $-0,29$ & $-1,38$ & 0,141 \\
\cline { 2 - 11 } & Female & 31,6 & 25,5 & 36,5 & 11,00 & 3,87 & 12,24 & $-0,49$ & 0,12 & 0,143 \\
\hline
\end{tabular}

Table 2 Differences between the hand grip strength of the right and left hand of students

\begin{tabular}{|c|c|c|c|c|c|c|c|c|}
\hline & \multirow[t]{2}{*}{ Mean $\pm S D$} & \multirow[t]{2}{*}{ Diff. } & \multirow[t]{2}{*}{$\mathrm{T}$} & \multirow[t]{2}{*}{ df } & \multirow{2}{*}{$\begin{array}{c}\mathrm{p} \\
\text { (2-sided) }\end{array}$} & \multicolumn{2}{|c|}{$\begin{array}{c}95 \% \text { Confidence } \\
\text { interval }\end{array}$} \\
\hline & & & & & & & Lower & Upper \\
\hline \multirow{2}{*}{$\begin{array}{l}\text { Male } \\
(16)\end{array}$} & Right arm & $49,10 \pm 6,63$ & \multirow{2}{*}{3,02} & \multirow{2}{*}{4,158} & \multirow{2}{*}{14} & \multirow{2}{*}{$0001^{* *}$} & \multirow{2}{*}{1,462} & \multirow{2}{*}{4,578} \\
\hline & Left arm & $46,08 \pm 6,37$ & & & & & & \\
\hline \multirow{2}{*}{$\begin{array}{c}\text { Female } \\
(6)\end{array}$} & Right arm & $35,60 \pm 4,91$ & \multirow{2}{*}{4,03} & \multirow{2}{*}{3,176} & \multirow{2}{*}{5} & \multirow{2}{*}{$0,025 *$} & \multirow{2}{*}{0,768} & \multirow{2}{*}{7,298} \\
\hline & Left arm & $31,57 \pm 3,86$ & & & & & & \\
\hline
\end{tabular}

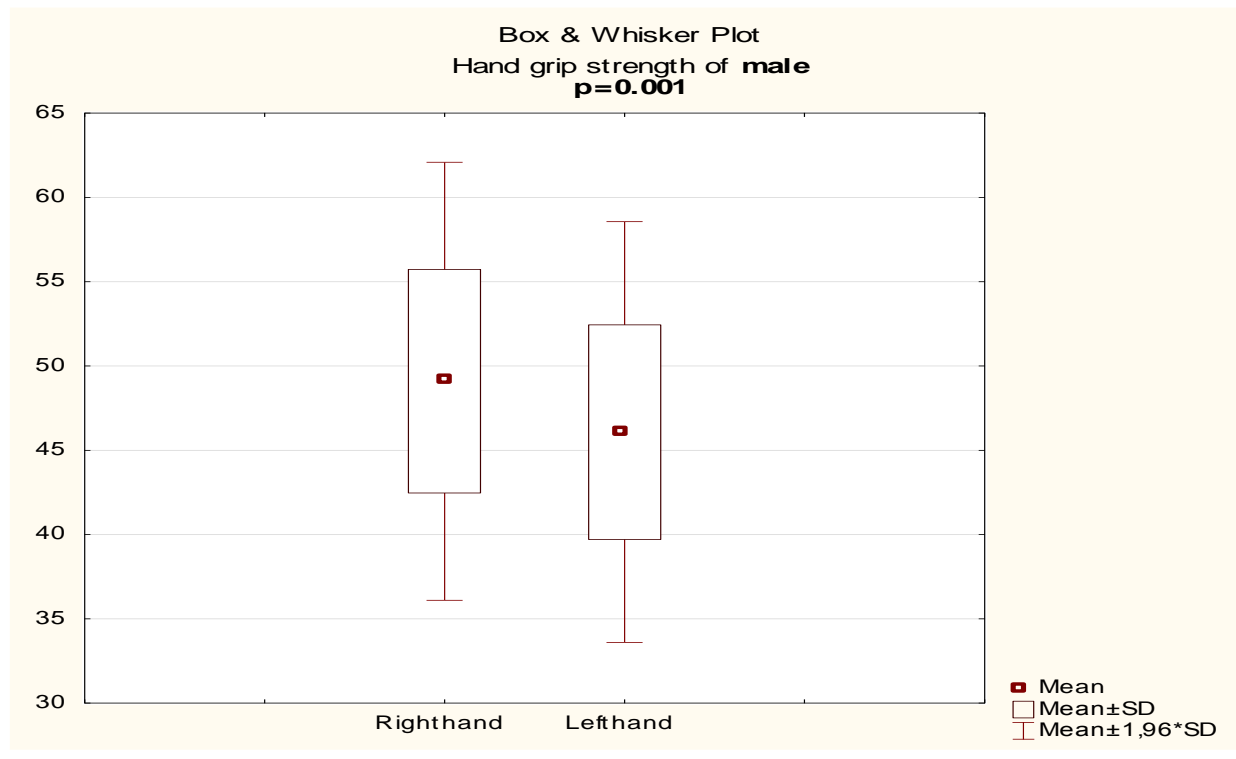

Figure 1 Differences between right and left hands- Male 


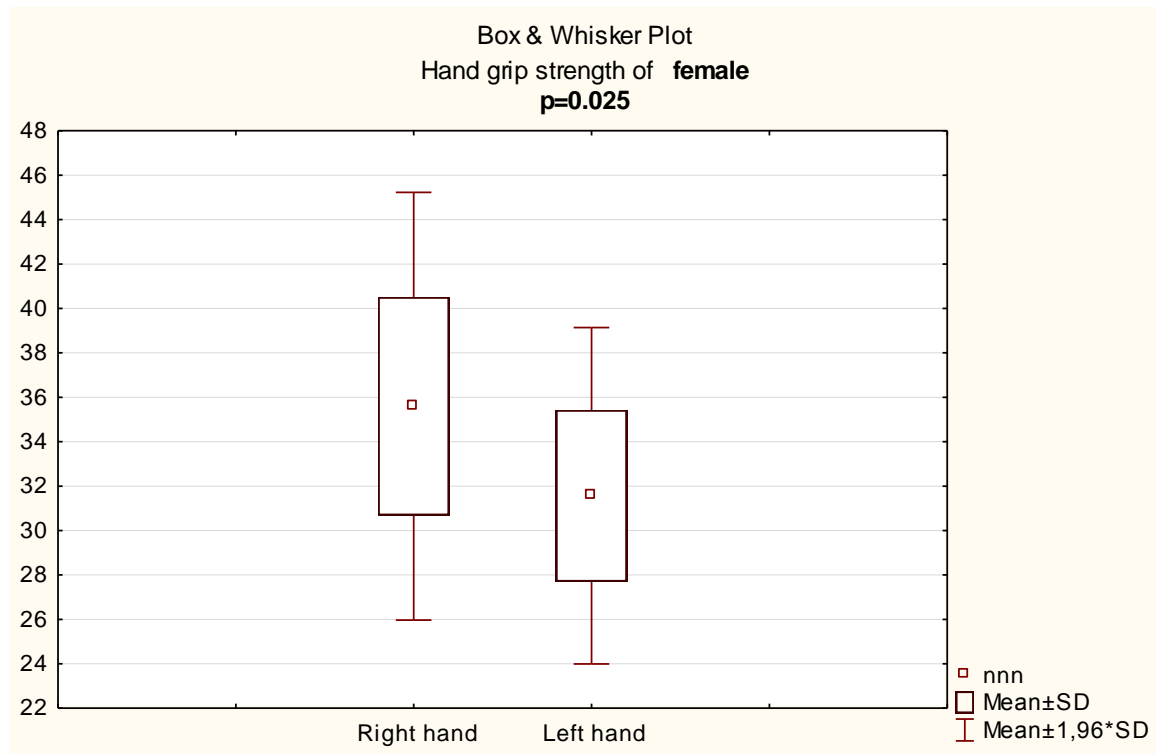

Figure 2 Differences between right and left hand-Female

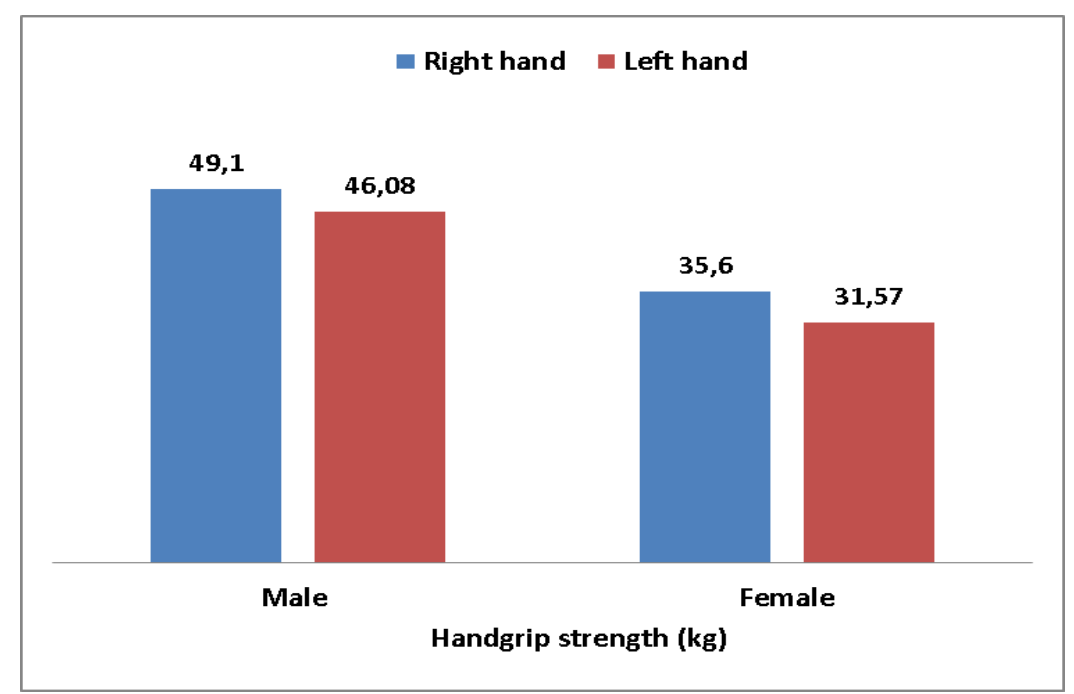

Figure 3 Differences of average values hand grip strength (same gender)

The maximum achieved strength with the right hand was $42.2 \mathrm{~kg}$, and the minimum was $28.9 \mathrm{~kg}$. The strength of the left arm of the female sample, as in flies, was lower on average, so the maximum grip strength was $36.5 \mathrm{~kg}$ and the minimum of $25.5 \mathrm{~kg}$ with a CV\% of 12.24 to 13.80 (Table 1). In general, all results (average, maximum and minimum values) of strength were higher in male subjects than in female subjects, as expected. Also in both subsamples, the right hand (dominant) proved to be stronger than the left. Table 2 contains the results of the T-test for both subsamples of subjects. Based on the obtained T-test results, it can be concluded that statistically significant differences were recorded in the maximum grip strength between the left and right arm of male students $(t=4.158, p<0.001)$ and between the grip strength of female students $(t=3.176, p<0.025)$ (Fig. 1 , 2, 3).

\section{Discussion}

For optimal hand function, it is necessary to preserve the range of motion in all joints of the upper extremity, the contractile ability of the muscles, endurance, as well as the function of the grip. Due to the fact that the hands are anatomically predetermined for various manipulative tasks, where during various physical and sports activities they produce the appropriate muscular force for gripping, which is manifested as hand grip force, therefore hand grip force is often recognized as a limiting factor in all manipulative activities realized by the cranial part of the body [1]. Muscle strength is an important aspect of 
physical fitness and health, where any decrease in muscle strength causes significant functional limitations. The dominant hand is considered to be the one that is used more often, it is faster and more precise when performing manual tasks, and the optimal range of motion in all joints of the upper extremity, contractile ability of muscles, endurance, as well as grip functions. Dominant lateralization means the appearance of the leading limb when performing complex psychomotor activities, and most often dominant lateralization appears as right-handed. According to Koley, et al., [21], hand grip characteristics are relatively predictable because they are directly related to morphological structure, training, fitness, health, and physiological condition at the time of testing. The subject of the current research involves the examination of the contractile characteristics of the hand as the basic manipulative organ with the main goal of the study to determine the maximum isometric muscle force of the hand grip and the difference in terms of full dimorphism of students. The obtained T-test results confirmed statistically significant differences between the so-called dominant and non-dominant hands between male subjects $(p<0.001)$ and between female subjects $(p<0.025)$, thus confirming significant dimorphism in both genders. The distribution of the results of the average values (Figure 3) partially confirms the " $10 \%$ rule", which implies that the strength of the dominant hand is $10 \%$ higher than the strength of the non-dominant hand [36]. Similar results to our study were obtained by Koley, \& Mahendra [5] who, among other anthropometric parameters, analyzed the grip strength of a cricketer's hand, and the results obtained served as criteria in the selection of candidates for this sport. The obtained results of our study, although on a smaller sample, are in line with the results of previous research $[12,13,23,36]$ that analyze anthropometric characteristics, where hand grip proved to be an indicator of the different anthropometric profile of the subjects. In terms of grip dominance and differences within the same gender, the results of this study confirm the dominance of righthanded people over left-handed ones, which supports previous research on this topic [21], as well as questions differences between the grip strength of subjects from urban and rural areas [37].

In our female sample, the maximum grip force of the left hand is $31.57 \mathrm{~kg} \pm 3.86 \mathrm{~kg}$ and the right hand $35.60 \pm 4.91 \mathrm{~kg}$, which is slightly higher than in the study of Kljajić, et al., [38] where the maximum grip force of the left hand grip was $28.72 \mathrm{~kg}$ and right was $31.47 \mathrm{~kg}$, i.e. the research of Dopsaj, et al., [39] where the maximum grip force of the left hand was $28.40 \mathrm{~kg}$ and for the right hand it was $31.10 \mathrm{~kg}$. Comparing the results between male subjects and both studies, it is found that our subjects had a stronger grip with the left $(46.08 \mathrm{~kg})$ and right hand $(49.10 \mathrm{~kg})$. This result is perhaps expected because our respondents are mostly active in sports activities and have a stronger hand grip than the respondents from the previous research, who may be expected to have a higher level of physical abilities, since they are students of the Criminal Police Academy.

The assessment of hand grip strength and endurance is applied in various areas of sports research. In the field of anthropometric measurements, hand grip characteristics are often compared and correlated with other physical characteristics, body height, BMI, and age $[40,41]$. In a large number of studies, the application of hand grip strength can be found in various sports, both in recreational and top athletes [34]. It is also important in monitoring physical and social factors in relation to the environment [41, 42] and as a measure of aggression and social competition among adolescents [43].

During life, arm strength develops in both genders, reaching a peak at 35 years of age and continuously decreasing, while the process of maturing limb dominance in the manipulative field ends somewhere between 6 and 8 years of age [38]. Anthropometric variables (forearm circumference and length, arm size, body weight) show a positive correlation with grip strength, while body mass index, type of work and hand dominance show only partial positive correlation or no correlation with grip strength [7]. These allegations are partly consistent with the results of a current study that recorded significant gender differences that are more pronounced in male students which is also consistent with some earlier research [2]. This distribution of our results is a consequence of the different body status of individuals of both genders, where body mass, height, individual longitudinal proportions, etc. are sometimes defined as the decisive factor in the grip strength of the hand [4, $7,11,44]$. Our research has shown that in female subjects, the dominant hand is stronger than the nondominant hand, which is in line with the above rule. In male respondents, this difference is smaller. In the research [45] it was found that the dominant hand in left-handed people is stronger than the non-dominant one by $11.2 \%$, while the dominant hand in righthanded people is only $2.4 \%$ stronger than the nondominant hand. A smaller difference in hand grip force 
between the right and left arm can also be found in other studies $[46,47]$ where the non-dominant arm is weaker than the dominant by $0.1-3 \%$. Allegations about the possible influence of morphological parameters on the grip strength justify the results of our study because our sample consists of students of physical education and sports, where each sport requires a certain morphological profile of an individual, hence the level of necessary strength. According to Chatterjee et al., [26] the grip strength of the right and left arm is positively correlated with weight, height and body surface area and is a significant determinant of bone mineral content and bone surface at the forearm sites thus achieving a positive correlation with lean body mass and physical activity. Some previous research Fry et al., [48] confirms that one's grip strength plays a key role in injury prevention and the overall development of physical strength and physical performance [49], while the contractile abilities of the hand muscles are of great importance in predicting functional limitations, motor disorders and are a good indicator of overall strength, so they can be used as early screening in detecting the danger of physical disability [38].

\section{Conclusion}

The research included the physically active population of physical education and sports students with the aim of analyzing possible differences in the gender dimorphism of students. The results confirmed significant differences of both subsamples between the dominant and non-dominant hand (male, $p<0.001$; female, $p<0.025$ ). The obtained results of this research will be used for analytical and diagnostic purposes with a wide range of activities in the population of physical education and sports students (assessment of physical ability, trends and tendencies to monitor and change abilities, influence on the implementation of certain curricula of some subjects studied at the faculty, etc.). This is the first research on this topic with students of physical education and sports. Next study, it would include a significantly larger sample of respondents, which would allow obtaining more significant conclusions.

\section{References}

[1] B. Tyldesley, J.I. Grieve, (1996). Muscles, nerves and movement: Kinesiology in daily living (Sec. Ed.) (pp.150-175). England: Blackwell Science LTD.

[2] H. Carreira, T.F. Amaral, C. Brás-Silva, MP. Bruno, M. Oliveira, N. Borges, Hand grip strength in a sample of 11 to 14 years old children, Acta Médica Portuguesa, 23 (5) (2010) 811-818. [PubMed]

[3] M. Vaz, S. Thangam, A. Prabhu, P.S Shetty, Maximal voluntary contraction as a functional indicator of adult chronic under nutrition, British Journal of Nutrition, 7(1) (1996) 9-15. [DOI] [PubMed]

[4] TH. Musa, W. Li, L. Xiaoshan, Y. Guo, Y. Wenjuan, Y. Xuan, P. Pu Yue, W. Pingmin, Association of normative values of grip strength with anthropometric variables among students, in Jiangsu Province, Homo, 69 (1-2) (2018) 70-76. [DOI] [PubMed]

[5] S. Koley, Y.K. Mahendra, An Association of Hand Grip Strength With Some Anthropometric Variables In Indian Cricket Players, Facta universitatis - series: Physical Education and Sport, 7(2) (2009) 113-123.

[6] Y. Beloosesky, A. Weiss, M. Manasian, M. Salai, Handgrip strength of the elderly after hip fracture repair correlates with functional outcome, Disability and Rehabilitation, 32 (5) (2010) 367-673. [DOI] [PubMed]

[7] MC. Gunther, A. Burger, M. Rickert, A. Crispin, UC. Schulz, Grip strenght in healthy Caucasian adults: reference values, Journal of Hand Surgery, 33(4) (2008) 558-565. [DOI] [PubMed]

[8] M. Dopsaj, J. Ivanović, M. Blagojević, G. Vučković, Descriptive, Functional and Sexual Dimorphism of Exsplosive Isometric Hand Grip Force in Healthy University Students in Serbia, Facta Universitatis Series: Physical Education and Sport, 7(2) (2009) 125 - 139.

[9] R.W. Bohannon, Dynamometer measurements of hand-grip strength predict multiple outcomes, Perceptual and Motor Skills, 93(2) (2001) 323328. [DOI] [PubMed]

[10] B.N. Davies, E.J. Greenwood, S.R. Jones, Gender difference in the relationship of performance in the handgrip and standing long jump tests to lean limb volume in young adults, European Journal of Applied Physiology, 58 (3) (1998) 315320. [DOI] [PubMed]

[11] F. Agazadeh, K. Lee, A. Waikar, Impact of anthropometric and personal variables on grip strength, Journal of Human Ergology, 22(2) (1993) 75-81. [PubMed]

[12] T. Jürimäe, T. Hurbo, J. Jürimäe, Relationship of handgrip strength with anthropometric and body composition variables in prepubertal children, Homo, 60 (3) (2009) 225-238. [DOI] [PubMed]

[13] S. Koley, S.B. Kumaar, The Relation Between Handgrip Strength and Selected HandAnthropometric Variables in Indian InterUniversity Softball Players, Facta universitatis series: Physical Education and Sport, 10 (1) 
(2012) 13-21.

[14] R. Cooper, D. Kuh, R. Hardy, Mortality Review Group; FALCon and HALCyon Study Teams. Objectively measured physical capability levels and mortality: systematic review and metaanalysis, BMJ. 9 (2010) 341:c4467. [DOI] [PubMed]

[15] H. Frederiksen, D. Gaist, H.C. Petersen, J. Hjelmborg, M. McGue, J. Vaupel, K. Christensen, Hand Grip Strength: A Phenotype Suitable for Identifying Genetic Variants Affecting Mid-and Late-Life Physical Functioning, Genetic Epidemiology, 23 (2) (2002) 110-122. [DOI] [PubMed]

[16] P. Watts, V. Newbury, J. Sulentic, Acute changes in handgrip strength, endurance, and blood lactate with sustained sport rock climbing, Journal of Sports Medicine and Physical Fitness, 36(4) (1996) 255-260. [PubMed]

[17] B. Tan, A.R. Aziz, K.C. Teh, H.C. Lee, Grip strength measurement in competitive ten - pin bowlers. Journal of Sports Medicine and Physical Fitness, 41(1) (2001) 68-72. [PubMed]

[18] D.J. Wassmer, S.J. Mookerjee, A descriptive profile of elite U.S. Women's collegiate field hockey players, J Sports Med Phys Fitness, 42(2)(2002) 165-171. [PubMed]

[19] N.C. Lucki, C.W. Nicolay, Phenotypic plasticity and functional asymmetry in response to grip forces exerted by intercollegiate tennis players, The American Journal of Human Biology. (19) (2007) 566-577. [DOI]

[20] D.R. Melrose, F.J. Spaniol, M.E. Bohling, R.A. Bonnette, Physiological and performance characteristics of adolescent club volleyball players, Journal of Strength and Conditioning Research, 21(2) (2007) 481-487. [DOI] [PubMed]

[21] S. Koley, S. Singh, S. Kaur, A study of arm anthropometric profile in Indian interuniversity basketball players, Serbian Journal of Sports Sciences, 5(1) (2002) 35-40.

[22] N.A. Incel, E. Ceceli, P.B. Durukan, H.R. Erdem, Z.R. Yorgancioglu, Grip strength: effect of hand dominance, Singapore Medical Journal, 43 (5) (2002) 234- 237. [PubMed]

[23] M. Dopsaj, N. Koropanovski, G. Vučković, M. Blagojević, B. Marinković, D. Miljuš, Maximal isometric hand grip force in well-trained university students in Serbia: Descriptive, functional and sexual dimorphic model, Serbian Journal of Sports Sciences, 1(4) (2007) 138-147.

[24] A.E.J. Miller, J.D. MacDougall, M.A. Tarnopolsky, D.G. Sale, Gender differences in strength and muscle fiber characteristics, European Journal of Applied Physiology and Occupational Physiology, 66(3) (1993) 254-262. [DOI]
[25] A.L. Hicks, J. Kent-Braun, D.S. Ditor, Sex differences in human skeletal muscle fatigue, Exercise and Sports Sciences Reviews, 29(3) (2001) 109-112. [DOI] [PubMed]

[26] S. Chatterjee, B.J. Chowdhuri, Comparison of grip strength and isometric endurance between the right and left hands of men and their relationship with age and other physical parameters, Journal of Human Ergology, 20 (1) (1991) 41-50. [PubMed]

[27] D. MacDougall, H. Wenger, H. Green, (1991). Physiological testing of the high performance athlete (Sec.Ed.). Champaign, Illinois, USA: Human Kinetics Books.

[28] G. Haff, M. Stone, H. O'Bryant, E. Harman, C. Dinan, R. Johnson, K.H. Han, Force-time dependent characteristics of dynamic and isometric muscle action, Journal of Strength and Conditioning Research, 11 (4) (1997) 269-272.

[29] E. Müller, U. Benko, C. Raschner, H. Schwameder, Specific fitness training and testing in competitive sports, Medicine and Science in Sports and Exercise, 32 (1) (2000) 216-220. [DOI] [PubMed]

[30] J. Ivanović, M. Dopsaj, Functional Dimorphism and Characteristics of Maximal Hand Grip Force in Top Level Female Athletes, Collegium Antropologicum, 36 (4) (2012) 1231-1240. [PubMed]

[31] L. Guidetti, A. Musulin, C. Baldari, Physiological factors in middleweight boxing performance, Journal of Sports Medicine and Physical Fitness, 42 (3) (2002) 309-314. [PubMed]

[32] L.V. Giles, E.C.Rhodes, J.E.Taunton, The physiology of rock climbing, Sports medicine, 36 (6) (2006) 529-545. [DOI] [PubMed]

[33] D. Leyk, W. Gorges, D. Ridder, M. Wunderlich, T. Ruther, A. Sievert, D. Essfeld, Hand grip strength of young men, women and highly trained female athletes, European Journal of Applied Physiology, 99(4) (2007) 415-421. [DOI] [PubMed]

[34] J. Ivanovic, N. Koropanovski, G. Vuckovic, R. Jankovic, D. Miljus, B. Marinkovic, D. Atanasov, M. Blagojevic, M. Dopsaj, Functional dimorphism and characteristics considering maximal hand grip force in top level athletes in the Republic of Serbia, Gazzetta Medica Italiana Archivio per le Scienze Mediche, 168 (5) (2009) 297-310.

[35] E.A. Kuzala, M.C. Vargo, The relationship between elbow position and grip strength, American Journal of Occupational Therapy, 46 (1992) 509-512. [DOI] [PubMed]

[36] C. Häger-Ros, B. Rösblad, Norms for grip strength in children aged 4-16 years, Acta Paedriatrica, 91 (6) (2002) 617-625. [DOI] [PubMed] 
[37] M. Kaur, Age-related changes in hand grip strength among rural and urban Haryanvi Jat females, Homo, 60 (5) (2009) 441-450. [DOI] [PubMed]

[38] D. Kljajić, F. Eminović, S. Trgovčević, R. Dimitrijević, M. Dopsaj, Functional Relationship of Non-Dominant and Dominant Hands in Motor Task-Fist Grip Endurance, Special education and Rehabilitation, 11(1) (2012) 67-85.

[39] M. Dopsaj, D. Kljajić, F. Eminović, M. Koropanovski, R. Dimitrijević, I. Stojković, Model indicators of muscle force characteristics in young and healthy individuals during motor task hand grip: a pilot study, Special education and rehabilitation, 10 (1) (2011) 15-36.

[40] N. Massy-Westropp, T. Gill, A. Taylor, R. Bohannon, C. Hill, Hand grip strength: age and gender stratified normative data in a populationbased study, BMC Research Notes, 4 (2011) 127. [DOI] [PubMed]

[41] M.G. Hossain, R. Zyroul, B.P. Pereira, T. Kamarul, Multiple regression analysis of factors influencing dominant hand grip strength in an adult Malaysian population, Journal of Hand Surgery (European Volume) 37 (1) (2012) 65-70. [DOI] [PubMed]

[42] S. Koley, A.P. Singh, Effect of hand dominance in grip strength in collegiate population of Amritsar, Punjab, India, Anthropologist, 12(1) (2010) 1316. [DOI]

[43] A. Gallup, D. O'Brien, D. White, D. Wilson, Handgrip strength and socially dominant behavior in male adolescents, Evolutionary Psychology, 8 (2) (2010) 229-243. [DOI]

[44] V. Fuster, A. Jerez, A. Ortega, Anthropometry and strength relationship: male-female differences, Anthropologischer Anzeiger, 56 (1) (1998) 49-56. [PubMed]

[45] K. Ertem, M. Inan, S. Yologlu, N. Elmali, A. Harma, S. Sahin, A. Bora, Effects of dominance, body mass index and age on grip and pinch strength, Isokinetics and Exercise Science, 11(4) (2003) 219-223. [DOI]

[46] C.A. Armstrong, J.A. Oldham, A comparison of dominant and non-dominant hand strength, Journal of Hand Surgery, 24(4) (1999) 421-425. [DOI] [PubMed]

[47] K. Ertem, A. Harma, A. Cetin, N. Elmali, S. Yologlu, H. Bostan, B. Sakarya, An investigation of hand dominance, average versus maximum grip strength, body mass index and ages as determinants for hand evaluation, Isokinetics and Exercise Science, 13 (3) (2005) 223-227. [DOI]

[48] A.C. Fry, D. Ciroslan, M.D. Fry, C.D. Le Roux, B.K.
Schiling, L.Z. F Chiu, Anthropometric and performance variables discriminating elite American junior men weightlifters, Journal of Strength and Conditioning Research, 20 (4) (2006) 861-866. [DOI] [PubMed]

[49] M.M. Samson, I.B. Meeuwsen, A. Crowe, J.A. Dessens, S.A. Duursma, H.J. Verhaar, Relationships between physical performance measures, age, height and body weight in healthy adults, Age Ageing, 29 (3) (2000) 235242. [DOI] [PubMed]

\section{Funding}

No funding was received to carry out this study

\section{Authors Contribution}

Both the authors equally contributed to this work. Both of them read and approved the final version of the draft.

\section{Ethics Approval}

Approval was sought from the institution ethics committee.

\section{Informed Consent}

Written consent was obtained from the participants

\section{Conflict of interest}

The Authors have no conflicts of interest to declare that they are relevant to the content of this article.

\section{Does this article screened for similarity? \\ Yes}

\section{About The License}

(C) The Author(s) 2021. The text of this article is open access and licensed under a Creative Commons Attribution 4.0 International License 